\title{
Some Effects of Respiration Inhibitors and $o$-Coumaric Acid on the Inhibition of Sporulation in Venturia inaequalis
}

\author{
By D. S. KIRKHAM AND A. E. FLOOD \\ East Malling Research Station, Kent
}

(Received 13 December 1962)

\begin{abstract}
SUMMARY
The non-competitive inhibitors fluoroacetate and arsenite inhibited sporulation and respiration of Venturia inaequalis (Cke.) Wint. to a greater extent than malonate. They also restricted growth. $O$-Coumaric acid acted similarly to the non-competitive inhibitors but, while not inhibiting growth, it caused changes in the colour of the mycelium, suggesting an altered metabolism. Arsenite increased $\alpha$-ketoglutarate in the medium and to some extent pyruvate, while $o$-coumaric acid produced only a slight increase in the concentration of pyruvate. No detectable amounts of succinic acid resulted from the presence of malonate. Injection of $o$-coumaric acid into scab-infected apple shoots decreased the incidence of disease; malonate had the opposite effect and was strongly phytotoxic.
\end{abstract}

\section{INTRODUCTION}

The production of conidia by phytopathogenic fungi is often essential to the local spread of disease. Venturia inaequalis, the causal fungus of the scab disease of apple, produces large numbers of conidia after establishment of ascospore infection early in the season. Restriction of sporulation after infection, whether by host resistance or by application of antisporulants, could therefore be important in controlling the disease. Kirkham $(1957 b, c)$ outlined the significance of phenolic host metabolites in resistance, and Kirkham \& Flood (1956) showed the activity of certain analogues of caffeic acid, including o-coumaric acid, as inhibitors of the sporulation of $V$. inaequalis. In the present paper the activity of $o$-coumaric acid is further investigated and compared with the effects of respiration inhibitors.

\section{METHODS}

Culture methods. A single conidial isolate of Venturia inaequalis (Cke.) Wint. (clone E 1; Kirkham, 1957 a) was used. Cultures were grown on filter-paper cylinders standing in $10 \%(\mathrm{w} / \mathrm{v})$ malt-extract solutions; sporulation was estimated turbidimetrically, the Spekker drum readings recorded being directly proportional to the number of conidia produced (Kirkham, 1956). There were six replicate cultures in each treatment and analyses of variance were made on the data. In sporulation tests the paper cylinder cultures were transferred at the end of the log phase of growth to media containing the inhibitors. For biochemical tests, the paper cylinder cultures were each rinsed aseptically in $100 \mathrm{ml}$. sterile distilled water towards the end of the log phase of growth and for the last 3 days of growth transferred 
to a simple medium (glucose, $1.5 \mathrm{~g}$.; $\mathrm{MgSO}_{4} .7 \mathrm{H}_{2} \mathrm{O}, 0.05 \mathrm{~g}$.; $\mathrm{KH}_{2} \mathrm{PO}_{4}, 0 \cdot 15 \mathrm{~g}$.; $100 \mathrm{ml}$. trace element solution; Kirkham, 1957 a) containing the inhibitors. The pathogen was also grown in surface culture in Roux bottles, each containing $100 \mathrm{ml} .10 \%$ (w/v) malt-extract solution to provide material for chemical analysis and measurement of respiration. Inhibitors were added during the $\log$ phase of growth. The $\mathrm{pH}$ values of media containing $o$-coumaric acid, malonic acid and transaconitic acid were adjusted with $2 \mathrm{~N}-\mathrm{NaOH}$ before use.

The in vivo test on shoots of Cox's Orange Pippin was conducted as described by Kirkham $(1957 c)$.

Analysis of culture filtrates for acids from the paper cylinder method. Twelve tubes were used for the analysis; the paper cylinders from each tube were removed and the culture medium bulked. Each paper cylinder was cut in half, the retaining ring removed and the papers unrolled; they were then transferred to beakers and covered with water. After gentle agitation for $10 \mathrm{~min}$. the fluid was decanted and the process repeated twice. The eluates and the bulked culture medium were combined, centrifuged to remove spores, poured into 4 vol. of boiling ethanol, held at the boil for $5 \mathrm{~min}$., then rapidly cooled and kept at $1^{\circ}$ overnight. Precipitated material was separated by centrifugation and the ethanol removed by distillation under reduced pressure in a nitrogen atmosphere at $30-35^{\circ}$. After bringing it to $\mathrm{pH} 7-8$, the aqueous residue (about $10 \mathrm{ml}$.) was extracted continuously with light petroleum $\left(60-80^{\circ}\right)$ for $6 \mathrm{hr}$. After removal of traces of light petroleum in a stream of nitrogen, the aqueous phase was shaken for $3 \mathrm{hr}$. with $1 \mathrm{~g}$. deactivated charcoal (Schramm $\&$ Primosigh, 1943) to remove pigments. The charcoal was separated by filtration and the filtrate and washings made to $50 \mathrm{ml}$. A sample of this solution was used for determining nitrogen (micro-Kjeldahl) and potassium (flame photometry). These figures enabled the size of the cation exchange column to be calculated. The remainder of the solution was brought to $\mathrm{pH} \mathrm{2-2.5}$ with $8 \mathrm{~N}$-acetic acid (Harris, Tigane \& Hanes, 1961) and passed through a column of Dowex $50 \times 4$ (100-200 mesh) in the hydrogen form. The eluate and washings were added to a column $(9 \times 0.6 \mathrm{~cm}$. diam.) of Dowex $1 \times 8(200-400 \mathrm{mesh})$ in the acetate form and the column washed until the eluate was free from sugar (Molisch test). The analysis of the absorbed acids was completed by gradient elution (Hulme \& Wooltorton, 1958).

Keto acid analysis of culture filtrates from Roux bottles. Two Roux bottle cultures were used for each treatrnent. After centrifugation and filtration through Celite as described above, metaphosphoric acid (100 ml. of a solution to give a final concentration of $0 \cdot 6 \mathrm{M}-\mathrm{HPO}_{3}$ ) was added to the clear filtrate, which was kept at $0^{\circ}$ until analysed. For the analysis, dinitrophenylhydrazine $(20 \mathrm{ml}$. of a $1 \%$ solution in $5 \mathrm{~N}-\mathrm{H}_{2} \mathrm{SO}_{4}$ ) was added; the mixture was brought to room temperature and allowed to stand for $45 \mathrm{~min}$. Dinitrophenylhydrazones of the keto acids were isolated by the method of Isherwood \& Niavis (1956) and then separated on a paper chromatogram and determined individually by the method of Isherwood \& Cruickshank (1954).

Measurement of respiration. Mycelium was removed from individual Roux bottles by filtration through muslin, washed with water to remove spores and culture medium, sucked dry on filter paper in a sintered-glass funnel, blotted for further drying, macerated for 5-10 min. in $0.05 \mathrm{M}-\mathrm{KH}_{2} \mathrm{PO}_{4}$, and the fluid adjusted to $\mathrm{pH} 6 \cdot 0$ with $2 \mathrm{~N}-\mathrm{NaOH}$. The extract was made up to be equivalent to about $50 \mathrm{mg}$ (wet wt.) 
mycelium/2.2 $\mathrm{ml}$. The inhibitors were used at $\mathrm{pH} \mathbf{6} \cdot \mathbf{0}$, except for the higher concentrations of $o$-coumarate and arsenite, which came out of solution below about pH 6.5 and had to be prepared immediately before use. Respiration was measured in a standard Warburg apparatus by the direct method, the inhibitors being added from the side arms of the flasks after a steady respiration rate had been attained.

\section{RESULTS}

Effects of inhibitors on growth and sporulation

Table 1 shows that malonate inhibited the sporulation of the pathogen. The degree of inhibition was dependent on the initial $\mathrm{pH}$ value of the transfer medium, being greater at $\mathrm{pH} 6 \cdot 2$ than at $\mathrm{pH} 4 \cdot 2$. In no case was the mycelial growth decreased in rate or amount.

Table 1. Inhibition by malonic acid of sporulation of Venturia inaequalis clone $\boldsymbol{E} 1$ grown in malt-extract solution

\section{Concentration of inhibitor}

(M)

$\overline{0.05}$

$0 \cdot 1$

0.04

$0 \cdot 1$

0.0125

0.025

0.05

$0 \cdot 1$

$$
\begin{gathered}
\text { Initial } \mathrm{pH} \\
\text { value }
\end{gathered}
$$

$4 \cdot 2$

$4 \cdot 2$

$4 \cdot 2$

5.0

$5 \cdot 0$

$5 \cdot 0$

$6 \cdot 2$

$6 \cdot 2$

$6 \cdot 2$

$6 \cdot 2$

$6 \cdot 2$

Sporulation*
$0 \cdot 661$
$0 \cdot 632$
$0 \cdot 402$
$0 \cdot 263$
$0 \cdot 281$
$0 \cdot 076$
$0 \cdot 456$
$0 \cdot 315$
$0 \cdot 196$
$0 \cdot 145$
$0 \cdot 018$

Level of significance

$P<0.01$

$P<0.001$

$P<0.001$

* Spekker drum reading of conidial suspension (directly proportional to the number of conidia).

The effect of malonate injection on inoculated shoots of Cox's Orange Pippin was also investigated. In a preliminary trial malonic acid $(0 \cdot 1 \mathrm{~m}$ at $\mathrm{pH} 5 \cdot 0)$ damaged the immature leaves when injected through the petioles below the shoot tips. Interveinal scorch and distortion gradually increased during the $\mathbf{5}$ days after injection until the leaves were all severely damaged. The concentration of the acid was therefore decreased to $0.05 \mathrm{M}$ in the main trial, where inoculated shoots were injected after the $36 \mathrm{hr}$. infection period ( 9 replicate shoots/treatment). Some slight damage again resulted but was insufficient to interfere with the expression of disease symptoms. Figure 1 shows that the incidence of disease was increased in the malonate treatment. In contrast with this result, the injection of similar host material with $o$-coumaric acid $(0 \cdot 1 \mathrm{M}$ at $\mathrm{pH} 7)$, after infection with Venturia inaequalis clone $\mathrm{E} 1$, caused a considerable degree of inhibition of the pathogen (Fig. 2) and was in no way damaging to the host.

Table 2 shows that arsenite and fluoroacetate were no more active as antisporulants than the competitive inhibitors (transaconitate, malonate; Table 1) and that where sporulation was markedly depressed mycelial growth was inhibited. Similarly, 
the respiration rate of mycelium was decreased much more by these inhibitors than by malonate. $o$-Coumarate, however, while having no effect on the rate and amount of growth, strongly inhibited both respiration and sporulation.

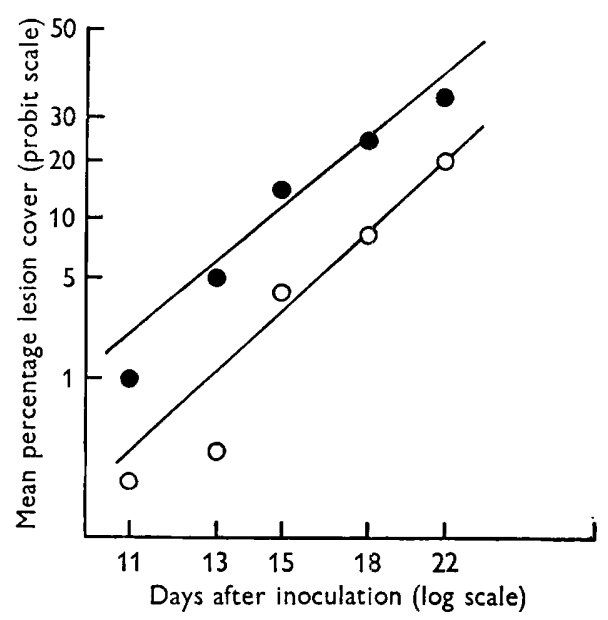

Fig. 1

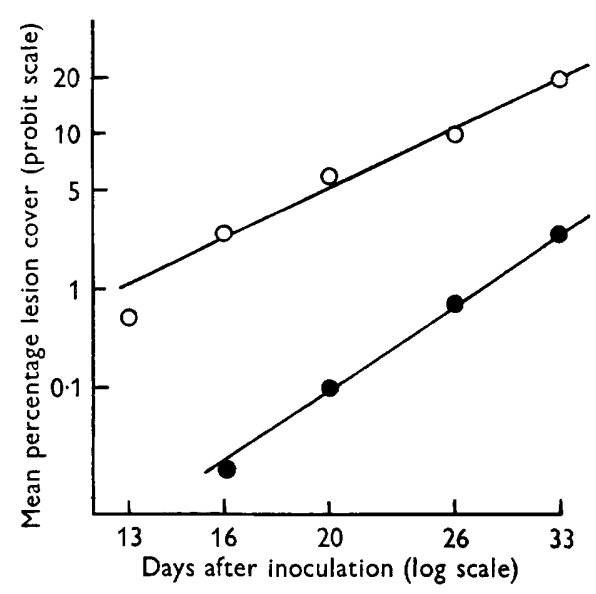

Fig. 2

Fig. 1. Stimulation of Venturia inaequalis clone $\mathrm{E} 1$ on the second fully expanded leaves of Cox shoots after injection of malonate below shoot tip. $O$, Control;, , sodium malonate.

Fig. 2. Inhibition of Venturia inaequalis clone $\mathrm{E} 1$ on Cox leaves after injection of $o$ coumarate. $O$, Control; 9 , sodium o-coumarate.

Table 2. Inhibition of Venturia inaequalis clone $E 1$, grown in $10 \%$ malt-extract solution at $\mathrm{pH} 6 \cdot 2$, by respiration inhibitors and o-coumaric acid

\begin{tabular}{|c|c|c|c|c|}
\hline Inhibitor & $\begin{array}{l}\text { Concentration } \\
\text { (M) }\end{array}$ & Sporulation* & $\begin{array}{l}\text { Growth } \dagger \\
\text { category }\end{array}$ & $\begin{array}{c}\text { Inhibition of } \\
\text { respiration } \ddagger \\
(\%)\end{array}$ \\
\hline- & - & 0.788 & 3 & - \\
\hline $\mathrm{Na}$ arsenite & $\begin{array}{l}0.005 \\
0.01 \\
0.1\end{array}$ & $\begin{array}{l}0 \cdot 472 \\
0 \cdot 270 \\
0 \cdot 001\end{array}$ & $\begin{array}{l}\mathbf{3} \\
\mathbf{2} \\
\mathbf{0}\end{array}$ & $\begin{array}{l}50 \\
50 \\
-\end{array}$ \\
\hline Na fluoroa cetate & $\begin{array}{l}0.0005 \\
0.001 \\
0.01\end{array}$ & $\begin{array}{l}0.568 \\
0 \cdot 280 \\
0.000\end{array}$ & $\begin{array}{l}2 \\
1 \\
0\end{array}$ & $\begin{array}{l}40 \\
40 \\
-\end{array}$ \\
\hline transAconitic acid & $\begin{array}{l}0 \cdot 05 \\
0 \cdot 1\end{array}$ & $\begin{array}{l}0 \cdot 129 \\
0 \cdot 055\end{array}$ & $\begin{array}{l}\mathbf{3} \\
\mathbf{3}\end{array}$ & - \\
\hline o-Coumaric acid & $\begin{array}{l}0 \cdot 01 \\
0 \cdot 05 \\
0 \cdot 1\end{array}$ & $\begin{array}{l}0 \cdot 227 \\
0 \cdot 024 \\
0 \cdot 020\end{array}$ & $\begin{array}{l}\mathbf{3} \\
\mathbf{3} \\
\mathbf{3}\end{array}$ & $\begin{array}{l}- \\
21 \\
92\end{array}$ \\
\hline Malonic acid & $0 \cdot 1$ & - & - & 20 \\
\hline
\end{tabular}




\section{Analysis of culture filtrates for acids}

The filtrates from two Roux bottle cultures were used for analysis in each case. Adding arsenite to these cultures, 22 days after inoculation, greatly increased pyruvate and $\alpha$-ketoglutarate concentrations as assessed at the end of the incubation period 15 days later (Table 3). Adding 0 -coumarate, however, only slightly increased the pyruvate concentration, and in similar cultures grown in the presence of malonate $(0 \cdot 1 \mathrm{M})$ no succinic acid was detected. Adding malonate or $o$-coumarate to Roux bottle cultures or to washed paper-cylinder cultures resulted in acid profiles which differed from the control; but most of the compounds produced are as yet unidentified and were present only in very small amounts. Thus, except for $\alpha$-ketoglutarate, there occurred no large amounts of those acids which would have been expected if a Krebs cycle were functioning. Oxaloacetic acid was detected in trace amounts in all the culture filtrates but not in the original medium.

Table 3. Production of keto acids by Venturia inaequalis in the presence of sporulation inhibitors added to the cultures during the log phase of growth

\begin{tabular}{|c|c|c|}
\hline Inhibitor & $\begin{array}{l}\text { Pyruvate } / 200 \mathrm{ml} \text {. } \\
\text { culture fluid } \\
\text { (mg.) }\end{array}$ & $\begin{array}{c}\alpha \text {-Keto- } \\
\text { glutarate } / 200 \mathrm{ml} . \\
\text { culture fluid } \\
(\mathrm{mg} .)\end{array}$ \\
\hline Control & $0 \cdot 72$ & $1 \cdot 8$ \\
\hline $\mathrm{Na}$ arsenite $(0.01 \mathrm{M})$ & $5 \cdot 5$ & $4 \cdot 1$ \\
\hline$o$-Coumaric acid $(0 \cdot 1 \mathrm{M})$ & $1 \cdot 4$ & $1 \cdot 9$ \\
\hline
\end{tabular}

\section{DISCUSSION}

Inhibition of sporulation of Venturia inaequalis by phenolic metabolites of the host (particularly depsides) may be important in the host relations of the pathogen. Structural analogues of caffeic acid, the active part of the chlorogenic acid molecule, have shown greatly increased activity, in vitro and in vivo; of these analogues $o$ coumaric acid has so far proved to be the most active antisporulant agent. An understanding of the mechanism of this action might provide clues to the nature of host resistance and to the type of chemical structure of potential value as an eradicant fungicide.

It seemed possible that the energy requirement for sporulation might be supplied by a respiration mechanism such as the Krebs cycle and that known inhibitors of this cycle might also inhibit sporulation. At about this time Behal (1959) published the results of a study of the effect of respiration inhibitors on the sporulation of Aspergillus niger. His results agree with ours, but in addition we have analysed the culture filtrates in the hope of detecting the expected accumulation of metabolites just before the inhibited stage of the metabolism.

Tables 1 and 2 show that the known competitive inhibitors were less active as antisporulant agents than the known non-competitive inhibitors and that the latter also restrict the growth of the pathogen. The activity of malonate is interesting, since it is generally agreed that malonate is most active at a low $\mathrm{pH}$ value, where it is predominantly undissociated, and in this form it penetrates plant tissue more readily than in the ionized form. Perhaps with Venturia inaequalis either the 
ionized and unionized forms of malonic acid penetrate the mycelium with equal ease or the inhibitory action occurs extracellularly and the ionized form is active (Turner \& Hanly, 1947). Succinate never accumulated with malonate inhibition. In fact no more than traces of it were detected in any of the culture filtrates. Assuming that malonate reached the site of the reaction under our experimental conditions and inhibited succinic dehydrogenase, the absence of increased quantities of succinate would suggest that succinic dehydrogenase is not active in $V$. inaequalis. Barinova (1960) concluded that succinic dehydrogenase did not participate in the metabolism of Rhizopus nigricans or Aspergillus niger growing in glucose media, but in the presence of malonic acid $(0.005-0.06 \mathrm{M})$ succinic acid production increased. However, because fumaric acid production also increased, Barinova suggested that the two processes of acid production were independent rather than linked as they would be in a Krebs cycle. When arsenite was used as an inhibitor, pyruvate and $\alpha$-ketoglutarate were found in increased quantities in the culture filtrates (Table 3). It would appear, therefore, that oxidative decarboxylation of pyruvate and $\alpha$-ketoglutarate plays a part in the metabolism of $V$. inaequalis. Walker, Hall \& Hopton (1951) described the production of pyruvate by $A$. niger as well as an unknown keto acid and a non-acidic carbonyl compound. Apart from pyruvate and $\alpha$-ketoglutarate, our culture filtrates all contained traces of oxaloacetate, but no other detectable carbonyl compounds. o-Coumarate, although inhibitory of sporulation, showed no similarity in action to any of the respiration inhibitors used, either in vitro or in vivo. Pyruvate production increased slightly (Table 3), but there was no increase in $\alpha$-ketoglutarate. Examination of the acid profile showed a number of minor differences from that produced by malonate, but neither profile differed strikingly from that of the control. In spite of the difficulty of obtaining satisfactory acid profiles, due to the production by $V$. inaequalis of many mostly unknown acids, each in a small quantity, it is clear that the mechanism of action of $o$-coumarate bears little resemblance to that of the respiration inhibitors tested. It appears therefore that $o$-coumarate either has a different effect on the tricarboxylic acid cycle or that the mechanism by which it inhibits sporulation is not concerned directly with this cycle. Since it is still uncertain whether a tricarboxylic acid cycle operates in $V$. inaequalis, it is possible that the action of the respiration inhibitors in decreasing sporulation might be unconnected with their known action on respiration. Further comment must await the results of investigations of the course of respiration in the fungus.

The authors thank Miss Erica Jacobs-Larkcom and Miss Christina Dexter for the Warburg determinations, Miss Jean Gooding for technical assistance and Mr D. H. Rees for the statistical treatment of the results.

\section{REFERENCES}

Barinova, G. A. (1960). The tricarboxylic acid cycle in molds. Microbiology, Moscow, $29,21$.

Behal, F. J. (1959). Biochemical studies of spore formation in Aspergillus niger. Arch. Biochem. Biophys. 84, 151.

Harris, C. K., Tigane, E. \& Hanes, C. S. (1961). Quantitative chromatographic methods. Part 7. Isolation of amino acids from serum and other fluids. Canad. J. Biochem. Physiol. 39, 439. 
Hulme, A. C. \& Wooltonton, L. S. C. (1958). Determination and isolation of the nonvolatile acids of pome fruits and a study of acid changes during storage. J. Sci. Fd Agric. 9, 150.

Isherwood, F. A. \& Cruickshank, D. H. (1954). Chromatographic separation and analysis of mixtures of pyruvic, oxalacetic and $\alpha$-ketoglutaric acids. Nature, Lond. $173,121$.

Isherwood, F. A. \& Niavis, C. A. (1956). Estimation of $\alpha$-keto acids in plant tissue: a critical study of various methods of extraction as applied to strawberry leaves, washed potato slices and peas. Biochem. J. 64, 549 .

KIRкham, D. S. (1956). A culture technique for Venturia spp. and a turbidimetric method for the estimation of comparative sporulation. Nature, Lond. 178, 550.

KIRkham, D. S. (1957 a). Relationships between cultural characters and pathogenicity in Venturia inaequalis and Venturia pirina. J. gen. Microbiol. 16, 360.

Krrкham, D. S. $(1957 b)$. Studies of the significance of polyphenolic host metabolites in the nutrition of Venturia inaequalis and Venturia pirina. J. gen. Microbiol. 17, 120.

KIRKнAM, D. S. $(\mathbf{1 9 5 7} \mathrm{c})$. The significance of polyphenolic metabolites of apple and pear in the host relations of Venturia inaequalis and Venturia pirina. J. gen. Microbiol. $17,491$.

Kirkham, D. S. \& Flood, A. E. (1956). Inhibition of Venturia spp. by analogues of host metabolites. Nature, Lond. 178, 422.

TURner, J. S. \& HANly, V. (1947). Malonate and plant respiration. Nature, Lond. 160, 296.

Schramm, Gerhard \& Primosigh, Josef (1943). Über die quantitative Trennung neutraler Aminosäuren durch Chromatographie. Ber. dtsch. Chem. Ges. 76, 373.

Walker, T. K., Hall, A. N. \& Hopton, J. W. (1951). Chromatographic detection of pyruvic, dimethylpyruvic and $\alpha$-ketoglutaric acids in cultures of Aspergillus niger on various substrates. Nature, Lond. 168, 1042. 